\title{
Central Nervous System Regulation of Liver and Adipose Tissue Metabolism
}

\author{
T. Shimazu \\ Department of Medical Biochemistry, School of Medicine, Ehime University, Shigenobu, Ehime, Japan
}

Summary. Hypothalamic and autonomic nervous regulation of carbohydrate and amino acid metabolism in the liver and of lipid metabolism in adipose tissues is described. The direct neural mechanism underlying this regulation has been evaluated. Electrical stimulation of the ventromedial hypothalamic nucleus (VMH)-splanchnic nerve system causes glycogenolysis in the liver by rapid activation of glycogen phosphorylase, whereas electrical stimulation of the lateral hypothalamic nucleus ( $\mathrm{LH}$ )-vagus nerve system promotes glycogenesis in the liver by activation of glycogen synthetase, through direct neural and neural-hormonal mechanisms. Studies on chemical coding of the hypothalamic neurones have revealed that norepinephrine-sensitive neurones in the VMH and acetylcholine-sensitive neurones in the LH are specifically involved in the regulation of liver phosphorylase and glycogen synthetase, respectively. Acetylcholine-sensitive neurones of the LH were also found to be concerned in regulation of hepatic tyrosine aminotransferase activity, through intermediation of the cholinergic system in the LH-vagal pathway. Finally, it has been shown that the VMH acts as a regulatory centre for lipolysis in adipose tissues by modulating activation of the sympathetic nervous system. In addition, stimulation of the VMH enhanced lipogenesis in brown adipose tissue preferentially, probably through a mechanism mediated by sympathetic innervation of this tissue. The latter finding suggests that both the breakdown and resynthesis of triglycerides in brown adipose tissue, but not in white adipose tissue, are accelerated by stimulation of the VMH.

Key words: Ventromedial hypothalamic nucleus, lateral hypothalamic nucleus, splanchnic nerves, vagus nerves, glycogenolysis, glycogenesis, lipolysis, lipogenesis, hypothalamic obesity, insulin, glucagon, calcium ions, phosphorylase, glycogen synthetase, tyrosine aminotransferase

\section{Organization \\ of the Hypothalamo-Autonomic Nervous System and Its Function in Metabolic Regulation}

Since the classical observation by Bernard in the 1850 's that puncture (piquire) of the floor of the fourth ventricle results in the appearance of transient glucosuria, the CNS has been implicated in the control of certain metabolic processes, mainly through neuroendocrine or hormonal regulation. However, whether this control is purely neural is conjectural, and direct proof for this postulation has only recently been obtained $[1,2]$. Although neural and hormonal regulation of metabolism are interrelated and act in coordination, neural regulation generally is fine and rapid, being suitable for emergency situations, whereas hormonal regulation is stable and suitable for supplementing and fortifying neural regulation.

Of central neural structures, the hypothalamus is regarded as an important integrative station for neural and hormonal regulation of peripheral metabolism. The hypothalamus is believed to be the highest autonomic centre that coordinates visceral activities in response to the ever-changing conditions of the internal and external environment, and it modulates hormonal secretion both through production of hypothalamic-releasing and inhibiting hormones and by sending neural signals to the endocrine organs.

In the hypothalamus there are groups of nerve cells or nuclei, which can be roughly divided structur- 


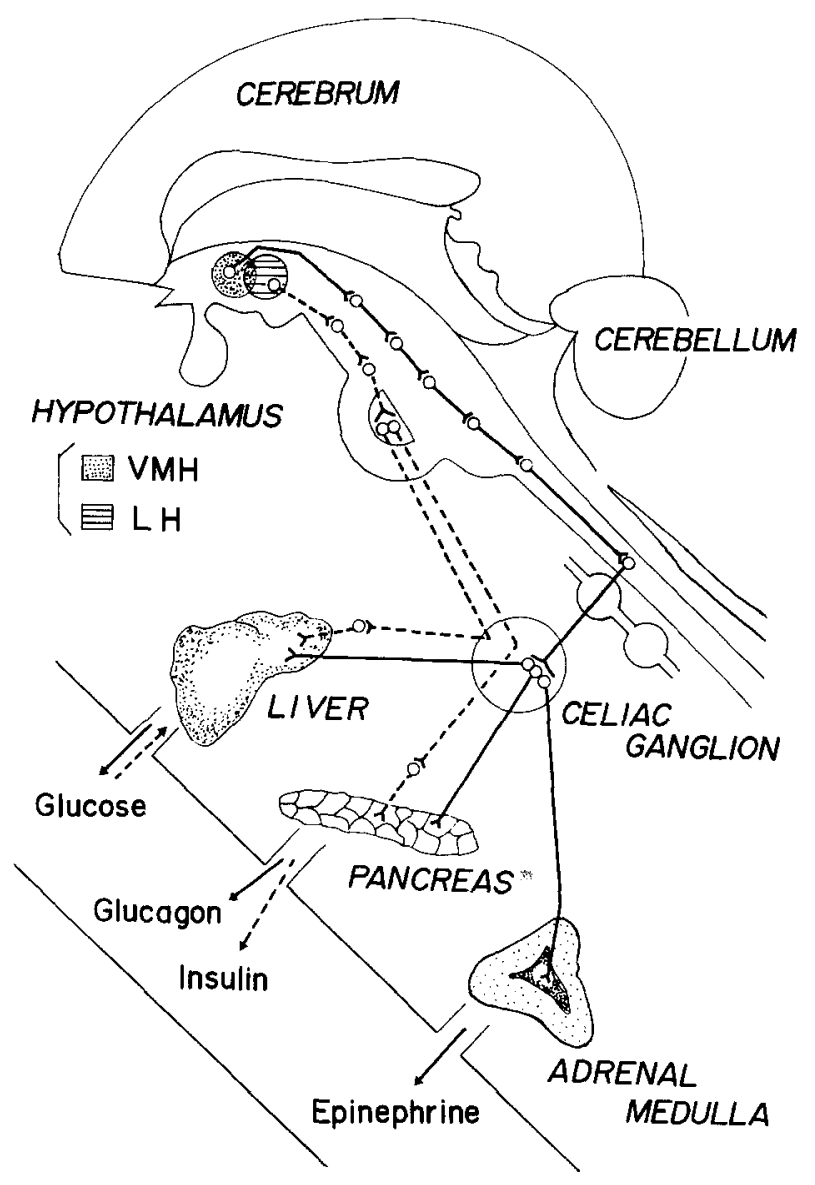

Fig. 1. Schematic representation of presumed connections between the hypothalamus and the autonomic nerves, and their innervation of visceral organs. The solid line indicates the VMH-splanchnic nerve pathway and the dotted line shows the LH-vagus nerve pathway

ally and functionally into the medial and the lateral hypothalamic areas at the boundary of the fornix. Although the medial hypothalamus actually contains several nuclei, including the anterior hypothalamic nucleus, ventromedial hypothalamic nucleus, dorsomedial hypothalamic nucleus, posterior hypothalamic nucleus, and dorsal and ventral premamillary nuclei, the ventromedial hypothalamic nucleus (VMH) has the central function. The lateral hypothalamus is composed of the lateral hypothalamic nucleus ( $\mathrm{LH})$, the cells of which are diffusely scattered amongst the upward and downward nerve fibres.

The VMH and LH are considered to act reciprocally in several regulatory functions. For regulation of food intake, for instance, the VMH is believed to act as the satiety centre while the LH acts as the feeding centre $[3,4]$. With respect to regulatory influences on autonomic nerves, the VMH belongs to the sympathetic system and the LH to the parasympathetic system $[5,6]$. In general, the functions of the
VMH and LH in metabolic regulation also seem to be reciprocal, particularly in the regulation of carbohydrate metabolism in the liver $[7,8]$. The reciprocal regulation parallels that of the sympathetic and parasympathetic nerves, as discussed later. Thus, the axons emerging from the VMH neurones are presumed to go through the midbrain, pons, medulla and the spinal cord to reach the intermediolateral cell column by polysynaptic pathways, which then communicate with the splanchnic nerves and the abdominal sympathetic nerves at the level of the thoracic cord. Similarly some of the LH neurones may connect with the vagus nerves at the level of the dorsal motor nucleus of the vagus of the medulla and form the LH-vagal circuit. These VMH-splanchnic and LH-vagal pathways then innervate various internal organs, thus mediating neural and neural-hormonal influences upon metabolic processes in the viscera (Fig. 1).

\section{Hypothalamo-Hepatic Axis in the Control of Carbohydrate Metabolism}

Evidence for reciprocal functions of the VMH and LH in the regulation of hepatic carbohydrate metabolism was obtained from studies of changes in liver glycogen metabolism after electrical stimulation of these hypothalamic nuclei [9]: stimulation of the VMH caused glycogenolysis in the liver, as indicated by the rapid rise in circulating glucose level and from the marked decrease in liver glycogen content with prolonged stimulation. Electrical stimulation of the LH, on the other hand, seemed to result in glycogen synthesis in the liver, since it caused a slight fall in blood glucose level and an insignificant increase in liver glycogen content with prolonged stimulation.

This work was later extended by analyzing changes in the activities of key hepatic enzymes involved in glycogen breakdown and synthesis [7, 10], i. e., glycogen phosphorylase (EC 2.4.1.1) and glycogen synthetase (EC 2.4.1.11). Phosphorylase and synthetase exist in the liver in two interconvertible forms; phosphorylase $a$ and synthetase $I$ are physiologically active, while phosphorylase $b$ and synthetase $D$ are essentially inactive in vivo. Therefore, the levels of phosphorylase $a$ and synthetase $I$ in the liver can be regarded as reflecting the rate of breakdown and synthesis of glycogen in the liver, respectively.

When the VMH of rats was stimulated electrically, the activity of liver phosphorylase $a$ increased rapidly and markedly, reaching a maximum activity of about 3-fold over unstimulated activity within $30 \mathrm{~s}$ [10]. This maximum level of phosphorylase $a$ was then maintained for $5 \mathrm{~min}$ of stimulation. The activity 
of synthetase $I$, on the other hand, did not change significantly on stimulation of the VMH. Conversely, on electrical stimulation of the $\mathrm{LH}$, an increase in the level of liver synthetase $I$ was observed [10]. A significant increase could be detected after $10-30 \mathrm{~min}$ of stimulation, and the level had increased about 2fold after $60 \mathrm{~min}$. Electrical stimulation of the $\mathrm{LH}$, however, caused little change in the activity of liver phosphorylase $a$.

These results indicate that electrical stimulation of the VMH causes glycogenolysis in the liver by rapid activation of glycogen phosphorylase, leading to a prompt rise in blood glucose, while stimulation of the LH promotes glycogen synthesis in the liver by activation of glycogen synthetase and leads to a rather slow and small decrease of blood glucose.

Since the above results were obtained with electrical stimulation, they raised the question of whether the hypothalamic effects on hepatic glycogen metabolism stem from activation of specific neurones in the hypothalamic nuclei or from activation of fibres that are merely passing through these areas. The hypothalamic nuclei possibly consist of a collection of different types of neurones. By employing a microinjection technique, it is possible to achieve chemical stimulation of a specific subset of neurones in the VMH and $\mathrm{LH}$ with different neurotransmitters, and to study "chemical coding" of the hypothalamic neurones in metabolic control [11-14].

As described above, the $\mathrm{VMH}$ is a sympathetic centre for controlling glycogen breakdown in the liver by increasing phosphorylase $a$ activity. To see what types of neurones of the VMH are concerned in regulation of hepatic glycogenolysis, the effect of chemical stimulation of the VMH on liver phosphorylase was studied $[13,14]$. Selective stimulation of the VMH neurones with norepinephrine resulted in an increase of liver phosphorylase $a$. Stimulation with other neurotransmitters, including dopamine, serotonin, acetylcholine, and $\gamma$-aminobutyric acid (GABA) had no effect on phosphorylase $a$ activity. The response of liver phosphorylase to noradrenergic stimulation of the VMH was very rapid, like that occurring after electrical stimulation, and attained a maximum within $1 \mathrm{~min}$ of the local application of norepinephrine. After $10 \mathrm{~min}$ it returned to the level of the control group similarly treated with saline. The maximal effect was obtained with a dose of norepinephrine of $5 \times 10^{-10}$ moles or more, a concentration that is well within the physiological range. The increase in liver phosphorylase $a$ activity after noradrenergic stimulation of the VMH was due to activation of the enzyme, i. e., to conversion of phosphorylase $b$ into the $a$ form, and not to new synthesis of enzyme protein.
The activation of liver phosphorylase after noradrenergic stimulation of the VMH was suppressed by previous treatment of the VMH neurones with local propranolol, but not with phentolamine [14]. These results suggest that norepinephrine-sensitive neurones in the VMH are specifically involved in regulation of phosphorylase activity in the liver and that the effect of norepinephrine is linked to $\beta$ adrenergic receptors in the hypothalamus. In addition, activation of liver phosphorylase by noradrenergic stimulation of the VMH was also blocked by previous IP injection of hexamethonium, a ganglionic blocking agent. This finding may be explained by supposing that the effect of norepinephrine-sensitive neurones of the VMH is mediated by peripheral sympathetic nerves. There is evidence that the splanchnic nerves exert direct neural control over liver phosphorylase [1, 15, 16], as discussed later. Rosenberg and DiStefano [17] and Ezdinli et al. [18] have also shown that the hyperglycaemia induced by systemic administration of epinephrine is inhibited by section of the medulla or the spinal cord. However, the influence of glycogenolytic hormones, particularly pancreatic hormones, on phosphorylase activation after hypothalamic stimulation has to be taken into account.

To characterize the $\mathrm{LH}$ neurones concerned with regulation of hepatic glycogen synthesis, the effect of chemical stimulation of the LH on liver synthetase was studied $[11,12]$. Cholinergic stimulation of the LH by microinjection of acetylcholine or carbachol resulted in a marked increase in synthetase $I$ activity. Since the total activity of synthetase ( $I$ plus $D$ forms) did not change appreciably, the ratio of synthetase $I$ to total synthetase must have increased remarkably; i. e., acetylcholine caused activation of the enzyme. The lowest effective dose of acetylcholine was $5 \times$ $10^{-10}$ moles, and the optimum dose was $5 \times 10^{-9}$ moles. Similar application of other neurotransmitters, including serotonin, norepinephrine, dopamine, and GABA, did not alter liver synthetase activity appreciably.

The effect of hypothalamic cholinergic stimulation on liver synthetase was blocked by previous local treatment of the $\mathrm{LH}$ neurones with anticholinergic agents, such as atropine and scopolamine [12]. Thus, acetylcholine injected into the $\mathrm{LH}$ seems to act through cholinergic (probably muscarinic) transmission in the LH. The fairly specific activation of liver synthetase, produced by cholinergic stimulation of the LH, and its blockade by central administration of anticholinergic agents strongly suggest that acetylcholine-sensitive neurones in the $\mathrm{LH}$ are involved in regulation of glycogen synthesis in the liver.

The activation of liver synthetase induced by cholinergic stimulation of the LH was also blocked 


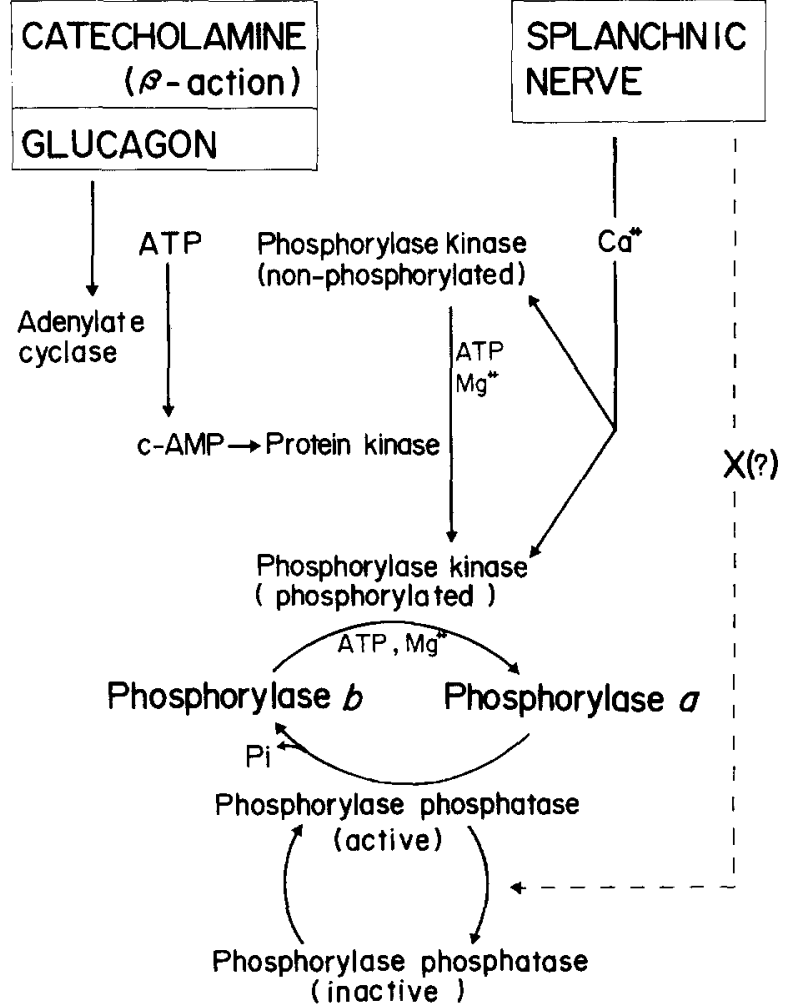

Fig. 2. Possible mechanisms for phosphorylase activation in liver by splanchnic-nerve stimulation and glycogenolytic hormones

completely by previous IP injection of N-methylatropine [12], an anticholinergic agent that does not readily penetrate the blood-brain barrier. This latter observation tends to confirm the idea that the effect of acetylcholine-sensitive neurones of the LH may be mediated by peripheral cholinergic nerves. As discussed later, the vagus nerves exert direct neural effects in regulation of liver glycogen synthesis $[19,20]$. Hence, the neural regulation of liver glycogen synthesis appears to be mediated centrally as well as peripherally by the cholinergic system.

The reciprocity of the VMH and $\mathrm{LH}$ has also been demonstrated in regulation of hepatic gluconeogenesis and glycolysis [21]. Electrical stimulation of the VMH caused an increase in the activity of phosphoenolpyruvate carboxykinase (PEPCK) (EC 4.1.1.32), a key gluconeogenic enzyme, and a marked suppression of pyruvate kinase (PK) (EC 2.7.1.40), a key glycolytic enzyme, in rat liver. Stimulation of the $\mathrm{LH}$, on the other hand, resulted in a decrease in PEPCK activity but did not alter PK activity. The maximum responses of these enzymes were obtained after $4 \mathrm{~h}$ of intermittent hypothalamic stimulation. These results suggest that the gluconeogenic process in the liver is enhanced by stimulation of the VMH and suppressed by stimulation of the $\mathrm{LH}$, while the glycolytic process is inhibited by
VMH stimulation. The stimulatory effect of the VMH on hepatic gluconeogenesis, presumably caused by the synergistic effects of increased adrenergic nervous activity and increased output of glucagon, is thus complementary to its glycogenolytic effect on the liver in producing hyperglycaemia. However, the gluconeogenic responses to VMH stimulation are rather slow reactions, unlike the glycogenolytic responses, which occur very rapidly $[9$, $10,22]$, and so are probably less important than the latter in an emergency.

\section{Neural-Metabolic Interaction in the Liver}

Both the sympathetic and parasympathetic nervous systems are important modulators of hepatic metabolism [2]. Nerves innervating the liver include sympathetic, parasympathetic and afferent components. The sympathetic fibres are derived from the splanchnic nerves and their postganglionic fibres originate in the celiac ganglia and plexus. The parasympathetic fibres are from the vagus nerves, and the ganglion cells concerned are located close to the liver. The liver cells are directly innervated. Electron microscopic studies $[23,24]$ have revealed nerve terminals making direct contact with hepatocytes. These terminals are commonly embedded in indentations in parenchymal cells and contain various numbers of both clear and dense-cored vesicles. Therefore, it appears that liver cells are subjected to direct neural control through both the sympathetic and parasympathetic nerves.

Afferent innervation of the liver may also be important for the sensory function of the liver [25]. Particularly because the liver is intimately involved in the metabolism and disposal of nutrients, metabolic receptors in the liver are presumed to inform the brain about the caloric content of ingested foodstuffs. It has been assumed, for instance, that afferent impulses from hypothetical hepatic glucoreceptors ascend through afferent fibres of the vagus [26-28], and that this information gets at least to the level of the hypothalamus [29-31]. Thus, the autonomic centre of the hypothalamus probably receives a constant afferent influx of glucose-related signals from the liver, which may interact with hypothalamic mechanisms controlling centrifugal influences upon hepatic carbohydrate metabolism and provide a feedback-control of glucose homeostasis.

The first evidence that hepatic glycogenolysis is under the direct control of hepatic sympathetic innervation was obtained in 1965 , when we demonstrated rapid rises in the activities of hepatic glycogenolytic enzymes (phosphorylase and glucose-6-phosphatase (EC 3.1.3.9)) and concomitant decreases in the liver 
glycogen content after electrical stimulation of the peripheral end of the left splanchnic nerves [32]. Subsequently, the roles of the peripheral autonomic nerves in regulating glycogen-metabolizing enzymes have been studied extensively $[1,15]$. The increase in phosphorylase and glucose-6-phosphatase activities in response to splanchnic-nerve stimulation reached a maximum within $30 \mathrm{~s}$ after the onset of stimulation, and the half-time of the increase was approximately $14 \mathrm{~s}$. These effects of splanchnic-nerve stimulation were completely counteracted by simultaneous stimulation of the vagus nerves, although vagal stimulation alone had little effect on the enzymes. The increase in phosphorylase activity caused by splanchnic-nerve stimulation was due to activation of the enzyme, i. e., conversion of the inactive phosphorylase $b$ to the active $a$ form, because the total amount of phosphorylase ( $b$ plus $a$ forms) was not altered appreciably by nerve stimulation. In the resting state, about a quarter of the total phosphorylase in the liver was active ( $a$ form). The amount of the active form increased to three-quarters of the total after 30-s stimulation of the splanchnic nerves, but was unchanged during vagal stimulation.

The activation of phosphorylase induced by splanchnic-nerve stimulation was not eliminated by adrenalectomy or pancreatectomy of the animals, indicating that epinephrine and glucagon are not necessary for the rapid activation of liver phosphorylase by splanchnic-nerve stimulation $[1,32]$. These findings show that the responses of glycogenolytic enzymes are directly dependent upon the integrity of hepatic sympathetic innervation. These enzymatic responses provide a satisfactory explanation for the hyperglycaemic and glycogenolytic effects of splanchnic-nerve stimulation in adrenalectomized and pancreatectomized animals of various species [33-37]. Edwards [33-35] showed that the hyperglycaemic response to splanchnic-nerve stimulation persisted after adrenalectomy or pancreatectomy, but that it was greatly reduced by section of the hepatic nerves.

The hepatic phosphorylase responded more rapidly to stimulation via sympathetic innervation than to intraportal administration of catecholamines; the latter effect was blocked by a $\beta$-adrenergic blocking agent, whereas the former effect was not [15]. The mechanism of phosphorylase activation by the splanchnic nerves was compared with those by catecholamines and glucagon [16]. The mechanism of phosphorylase activation by catecholamines via a $\beta$ adrenergic receptor and by glucagon has been well established: A cyclic AMP-initiated cascade reaction leads to activation of a protein kinase, phosphorylase kinase (EC 2.7.1.38), and phosphorylase (Fig. 2). In contrast, splanchnic-nerve stimulation was found to

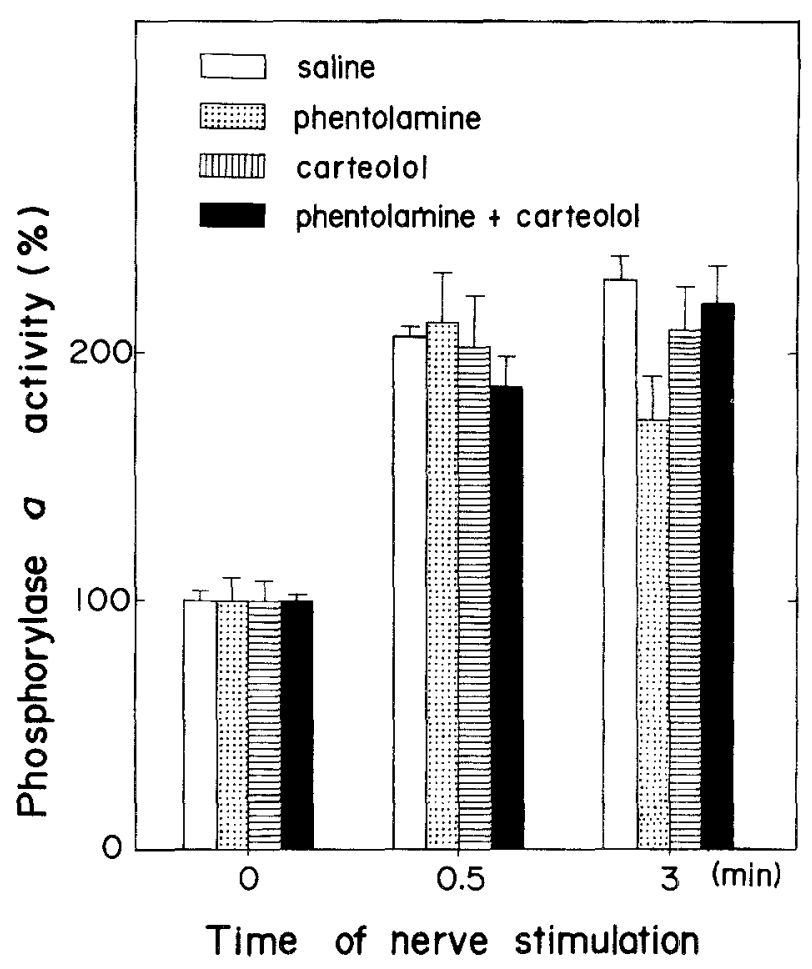

Fig. 3. Effects of adrenergic blocking agents on the response of liver phosphorylase to splanchnic-nerve stimulation in rabbits. Animals treated with phentolamine were given a priming injection ( $4 \mathrm{mg} / \mathrm{kg}$, IP) $60 \mathrm{~min}$ before stimulation, followed by constant intraportal infusion $(86 \mathrm{ul} / \mathrm{min})$ at a dose of $0.17 \mathrm{mg} / \mathrm{min}$ starting $20 \mathrm{~min}$ before stimulation and continuing until the end of stimulation. Carteolol was injected IP at a dose of $1 \mathrm{mg} / \mathrm{kg}, 90 \mathrm{~min}$ before nerve stimulation. For rabbits treated with both phentolamine and carteolol, a priming injection of phentolamine was omitted. Control animals were injected IP with $0.154 \mathrm{~mol} / \mathrm{l}$ saline. Phosphorylase $a$ activities are expressed as percentages of those before nerve stimulation. Columns and bars are means and SEM of values in 5-8 animals

cause a rapid increase in the phosphorylase a content without increase in the levels of cyclic AMP, cyclic AMP-dependent protein kinase, and phosphorylase kinase [16]. These results indicate that the activation of hepatic phosphorylase after splanchnic-nerve stimulation, unlike that induced by the $\beta$-adrenergic action of catecholamines and by glucagon, is not mediated by cyclic AMP and subsequent activations of protein kinase and phosphorylase kinase.

Instead, the effect of splanchnic-nerve stimulation may be mediated by an $\alpha$-adrenergic action of norepinephrine released in nerve terminals. This idea is supported by recent reports of Seydoux et al. [37] and Proost et al. [38] that neurally induced glucose output and phosphorylase activation was significantly inhibited by the $\alpha$-adrenergic blocking agent phentolamine. Recent evidence has suggested that interaction of catecholamines ( $\alpha$-agonists) with the $\alpha$ adrenergic receptor causes a mobilization of $\mathrm{Ca}^{2+}$ ions from mitochondria and other intracellular stores 


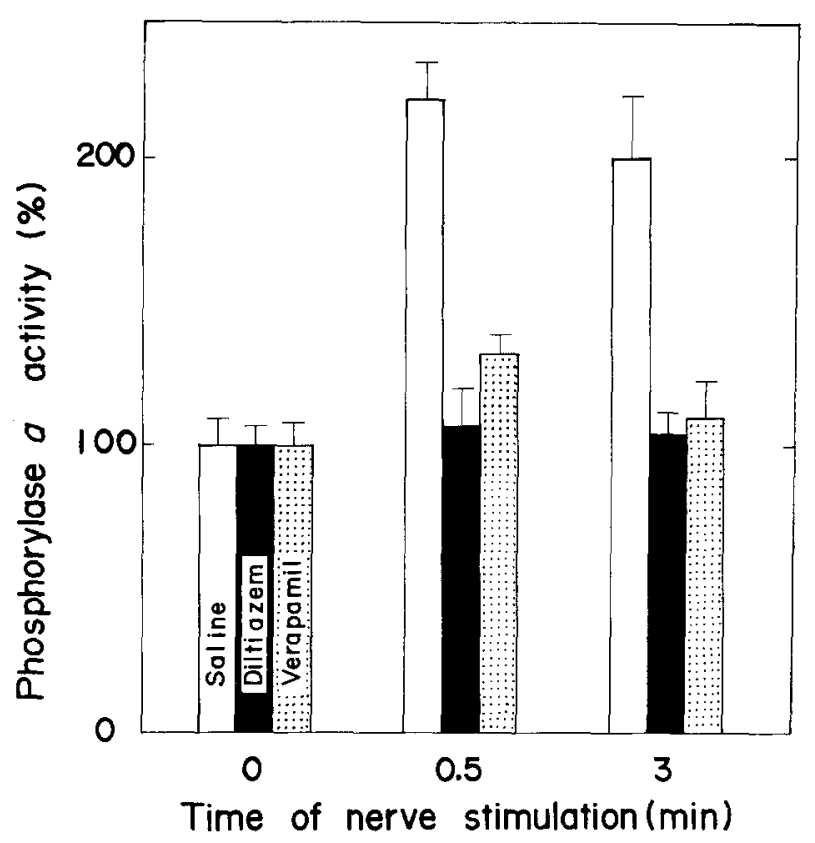

Fig. 4. Suppressive effect of $\mathrm{Ca}^{2+}$-antagonistic drugs on phosphorylase activation in rabbit liver after splanchnic-nerve stimulation. Diltiazem and Verapamil were given by constant intraportal infusion $(86 \mu \mathrm{l} / \mathrm{min})$ at doses of $0.17 \mathrm{mg} / \mathrm{min}$, starting $20 \mathrm{~min}$ before splanchnic-nerve stimulation and continuing until the end of stimulation. Saline $(0.154 \mathrm{~mol} / \mathrm{l})$ was similarly infused in a group of control rabbits. Phosphorylase $a$ activities are expressed as percentages of those before nerve stimulation. Columns and bars are means and SEM of values in 5-6 animals

in liver cells. Thus, the mobilization of internal $\mathrm{Ca}^{2+}$ and an increase in cytosolic $\mathrm{Ca}^{2+}$ ion concentration are the major mechanisms of the $\alpha$-adrenergic receptor system (for reviews, see $[39,40]$ ).

In our experiments shown in Figure 3, however, activation of liver phosphorylase produced by splanchnic-nerve stimulation was not prevented by intraportal infusion of phentolamine, nor by previous IP injection of the potent $\beta$-adrenergic blocking agent carteolol [41] at a dose that effectively suppressed the norepinephrine effect, or with both antagonists together. Nonetheless, the phosphorylaseactivating effect of nerve stimulation was completely blocked by the infusion of Diltiazem and Verapamil, $\mathrm{Ca}^{2+}$-antagonistic drugs that restrict calcium influx across the cell membrane (Fig. 4). These findings suggest that the influx of extracellular $\mathrm{Ca}^{2+}$, rather than mobilization of intracellular $\mathrm{Ca}^{2+}$, is tightly coupled with nerve stimulation. In addition, the effect of splanchnic-nerve stimulation was also blocked by intraportal infusion of indomethacin (data not shown), implicating the involvement of prostaglandins in its mechanism.

Whether the $\alpha$-receptor is involved or not in the mechanism by which splanchnic-nerve stimulation can activate liver phosphorylase, it may be agreed that the primary intracellular signal is a rise in cytosolic $\mathrm{Ca}^{2+}$. The cytosolic $\mathrm{Ca}^{2+}$ ions lead to the stimulation of phosphorylase kinase $[16,42]$ in a manner independent of cyclic AMP (see Fig. 2), but presumably in a manner analogous to that found recently for skeletal muscle phosphorylase kinase: as shown by Cohen et al. [43], besides the known regulatory $(\alpha$ and $\beta)$ and catalytic $(\gamma)$ subunits of rabbit skeletal muscle phosphorylase kinase, there is a fourth calcium-binding subunit ( $\delta$-subunit), which is very similar or identical to the $\mathrm{Ca}^{2+}$-dependent modulator protein (calmodulin); binding of $\mathrm{Ca}^{2+}$ to the $\delta$-subunit is thought to result in stronger interaction of this subunit with one of the regulatory subunits $(\alpha$ or $\beta$ ) thereby relieving inhibition on the catalytic $(\gamma)$ subunit.

Another possible explanation for the rise in phosphorylase $a$ activity after splanchnic-nerve stimulation is that it may be due to inactivation of phosphorylase phosphatase (EC 3.1.3.17), presumably mediated by some unknown factor other than norepinephrine or $\mathrm{Ca}^{2+}$ ions [16]. Phosphorylase phosphatase is known to counteract the activation of phosphorylase by phosphorylase kinase, and hence regulation of this enzyme is another likely point of control of phosphorylase activity (see Fig. 2). In connection with this possibility, we have isolated a factor from rabbit liver that can inactivate liver phosphorylase phosphatase, and by purification, this factor (named inactivating factor) has been identified as glutathione (GSSG) [44]. Incubation of the highly purified catalytic subunit of phosphorylase phosphatase (mol. wt., $3.3 \times 10^{4}$ ) with the isolated inactivating factor or GSSG converted the enzyme to a stable, less active form. Homogeneous phosphorylase phosphatase was found to contain two sulfhydryl groups per mole of catalytic subunit, one of which reacted with GSSG to form a mixed disulfide, thereby inactivating the enzyme [45]. Injection of GSSG into the portal vein of rabbits caused a rapid increase in phosphorylase $a$ activity in the liver [44]. Thus it seems likely that GSSG participates in regulation of phosphorylase activity in vivo, by inactivating phosphorylase phosphatase in the liver. However, to date there is no evidence that GSSG is involved in mediation of phosphorylase activation after splanchnic-nerve stimulation.

Besides the role of the sympathetic nerves in control of phosphorylase activity and glycogenolysis, the role of the parasympathetic nerves in regulating glycogen synthetase and glycogen synthesis in the liver has also been elucidated $[19,20,46]$. The activity of liver synthetase was greatly increased by electrical stimulation of the peripheral end of the vagus nerves, but it was slightly decreased by splanchnic-nerve stimulation. The increase in enzymatic activity on 
vagal stimulation attained nearly a maximum within $10 \mathrm{~min}$, and was shown to be due to conversion of the inactive form of the enzyme $(D)$ to the active form (I). The effect of vagal stimulation on synthetase was not eliminated by previous pancreatectomy, indicating that the effect was not a secondary effect mediated by insulin. However, the effect was completely counteracted by simultaneous stimulation of the splanchnic nerves $[20,46]$.

The activation of synthetase induced by vagal stimulation actually reflects an increased rate of glycogen synthesis in the liver [19]. On vagal stimulation, the rate of incorporation of radioactive glucose into liver glycogen in vivo was markedly enhanced; on splanchnic-nerve stimulation, the opposite effect was observed. The possibility that the increased rate of glycogen synthesis in response to vagal stimulation might be mediated indirectly by release of insulin from the pancreas was investigated by repeating the experiment on pancreatectomized animals. In these animals, a pronounced rise in glucose incorporation occurred on vagal stimulation, but the increase was somewhat less than that in intact animals. This suggests that the effect of vagal stimulation in increasing the rate of glycogen synthesis can be due mainly, if not entirely, to direct neural control. Further evidence for the parasympathetic nervous regulation of liver glycogen synthesis is that acetylcholine can stimulate glycogen synthetase in isolated, perfused rat liver [47] and in isolated hepatocytes [48]. Acute vagotomy in rats diminishes the rate of hepatic glycogen deposition after glucose load [49]. Therefore, the mediator for the parasympathetic nervous regulation of liver glycogen synthesis is probably acetylcholine.

In the light of these observations, it is clear that glycogen synthesis in the liver is enhanced by the direct action of the parasympathetic nerves through activation of glycogen synthetase, while glycogenolysis in the liver is stimulated by the sympathetic nerves through activation of phosphorylase and glucose-6phosphatase. Furthermore, the above findings, together with the demonstration of hypothalamic control of liver glycogen metabolism discussed earlier, suggest that a cholinergic component in the LHvagal pathway mediates the neural regulation of glycogen synthesis in the liver, and that a noradrenergic component in the VMH-splanchnic nerve pathway is an opposing neural regulatory system for controlling glycogen breakdown and glucose output by the liver.

\section{Neural-Hormonal Background Involved in Hypothalamic Control}

Hepatic glycogenolysis may be regarded as an emergency reaction to meet the extra metabolic requirements of the tissues during stress, and it is not surprising, therefore, that the hypothalamus and the sympathetic nervous system exert a prominent role in this process. There are at least three separate mechanisms by which the sympathetic nervous system can activate hepatic glycogenolysis and rapidly supply the circulating blood with glucose: first, directly via the hepatic innervation; second, by the release of epinephrine from the adrenal medulla; and third, by the release of glucagon from the pancreatic islets. All three mechanisms are presumed to be integrated in the hypothalamus and to act in coordination (see Fig. 1).

Conversely to glycogenolysis, hepatic glycogen synthesis is a reaction for energy storage, and the process can be stimulated by mechanisms involving the direct action of hepatic parasympathetic nerves and neural stimulation of the release of insulin from the pancreas, both of which are also under the integrative control of the hypothalamus. Thus, the hypothalamic control of hepatic glycogenolysis and glycogen synthesis mentioned in the preceding section appears to be exerted both by neural messages transmitted from the hypothalamus to the liver via the autonomic nerves, and by hormonal messages intervening between the nerves and the liver.

It is well known that hypothalamic and sympathetic excitation causes the liberation of epinephrine from the adrenal medulla. There is now abundant evidence to show that autonomic innervation of the pancreatic islets modulates the secretion of both glucagon and insulin (for reviews, see $[50,51]$ ). Secretion of glucagon from the pancreatic A-cells is enhanced by electrical stimulation of the splanchnic sympathetic nerves, while the secretion of insulin from the pancreatic B-cells is inhibited by splanchnic-nerve stimulation and enhanced by stimulation of the vagal parasympathetic nerves. Sympathetic and parasympathetic influences via the hypothalamus can also affect the endocrine pancreas. Electrical stimulation of the $\mathrm{VMH}$ causes a rapid rise in plasma glucagon $[22,52]$. Conversely, lesions of the VMH lead to an acute [53] as well as a chronic [54-57] increase in the circulating level of insulin. The increased secretion of insulin may result from increased tone of the parasympathetic nervous system due to $\mathrm{VMH}$ lesions, since the VMH is the presumed hypothalamic sympathetic centre $[2,5,6]$ and its destruction may lead to relative predominance of the other branch of the autonomic nervous system. Indeed, hyperinsulinaemia induced by VMH lesions has been shown to be reversed by subdiaphragmatic vagotomy $[53,58]$. Electrical stimulation of the $\mathrm{LH}$, on the other hand, fails to increase insulin secretion or change the plasma glucagon concentration [10, 52]. 


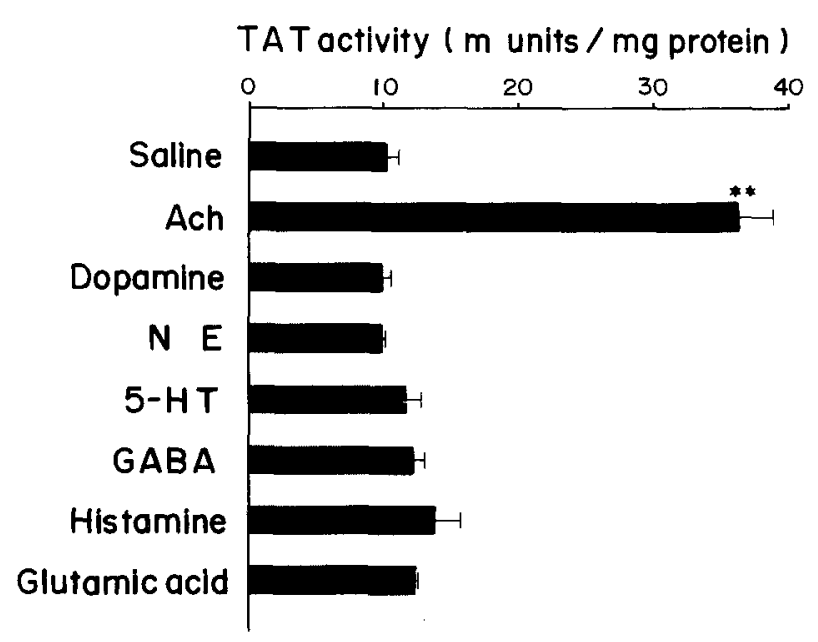

Fig. 5. Effects of microinjection of various neurotransmitters into the LH on tyrosine aminotransferase (TAT) activity in rat liver. Different neurotransmitters $\left(5 \times 10^{-8} \mathrm{~mol}\right.$ in $1 \mu \mathrm{l}$ of $0.154 \mathrm{~mol} / 1$ saline) and saline only were each injected into the $\mathrm{LH}$ in a single dose. The activity of tyrosine aminotransferase (TAT) in the liver was measured $4 \mathrm{~h}$ after the injection. Columns and bars are means + SEM of values in 4-7 rats. Ach, acetylcholine; NE, norepinephrine; 5-HT, serotonin; GABA, $\gamma$-aminobutyric acid. ** Significantly different from the control group treated with saline at $P<0.01$

Recent studies [52, 59] on chemical stimulation of the hypothalamus have revealed further characteristics of hypothalamic neurones concerned in regulation of glucagon and insulin secretion. Microinjection of norepinephrine [59] or epinephrine [52] into the VMH was shown to induce secretion of both glucagon and insulin, while microinjection of acetylcholine [52], probably through activation of nicotinic receptors in the $\mathrm{VMH}$, caused selective release of glucagon. On the other hand, chemical stimulation of the LH with norepinephrine [59] or epinephrine [52] could induce a preferential rise in plasma insulin level without a significant change in the glucagon level. Microinjection of dopamine, serotonin, and GABA into the VMH or the LH was without effect [52].

Frohman and Bernardis [22] analyzed the neuralhormonal mechanisms of hypothalamic control of glucose metabolism. In anaesthetized rats they observed a rapid rise in the plasma glucose level with a peak at 10-15 min after VMH stimulation, but not after LH stimulation. The role of the adrenal and the pancreas in this hyperglycaemic response was studied. Adrenalectomy did not inhibit the initial rise in glucose after VMH stimulation but impaired the response at 10 and $15 \mathrm{~min}$. As mentioned above, the plasma glucagon level was elevated by VMH stimulation. Nevertheless, prior injection of antiglucagon serum impaired, but did not abolish the early hyperglycaemic response to $\mathrm{VMH}$ stimulation, indicating that the role of glucagon in this response was also related to maintenance, rather than initiation, of hyperglycaemia.

It thus seems clear that the hypothalamus has a dual mechanism of control of liver glycogen metabolism and glucose homeostasis: one mechanism is by direct neural innervation of the liver, via the VMHsplanchnic nerve and the LH-vagus nerve pathways, which directly controls the enzymes metabolizing glycogen in the liver and thus is responsible for the initial and fine regulation of metabolic changes. The other mechanism is the neural-hormonal regulation of glycogen breakdown and synthesis described above, which is responsible for prolongation or consolidation of metabolic changes rather than for their initiation.

\section{Hypothalamo-Hepatic Relation in the Control of Amino Acid Metabolism}

The diencephalon has been suspected for many years to house a "protein metabolism centre". The involvement of the hypothalamus in regulation of amino acid metabolism was suggested in our early studies $[60,61]$ on the effects of electrical stimulation of the VMH and LH upon tryptophan pyrrolase (EC 1.13.1.12), an enzyme catalyzing the first step of tryptophan metabolism in the liver. Stimulation of the VMH or LH both markedly increased the activity of this enzyme, but their effects were different: stimulation of the VMH resulted in more than a 3fold increase in the total activity of enzyme and about half the enzyme was saturated with respect to its cofactor (ironporphyrin), in vivo; stimulation of the $\mathrm{LH}$ also resulted in about a 3 -fold increase in total enzyme activity, but only one-fifth of the enzyme was combined with cofactor. Thus, more apo-enzyme protein would be accumulated on LH stimulation than on VMH stimulation. Since this enzyme is known to be induced by cortisone administration, the observed effects might have been due to a hypothalamo-neuroendocrine effect on the adrenal. However, bilateral adrenalectomy did not abolish the effects of electrical stimulation of the $\mathrm{VMH}$ and $\mathrm{LH}$ [61], indicating significant involvement of other hypothalamo-autonomic nerves in enzyme regulation.

Black and Reis [62] showed that electrical stimulation of the vagus nerves or administration of carbachol in adrenalectomized rats induces the activity of liver tyrosine aminotransferase (EC 2.6.1.5), an enzyme catalyzing the first reaction in the pathway by which tyrosine is finally degraded to acetoacetate and fumarate. As an extension of our previous studies [11-14] on chemical coding of the hypothalamic neurones in metabolic control, we have investigated 
the hypothalamic control of this hepatic enzyme by selectively stimulating the $\mathrm{LH}$, a presumed parasympathetic centre $[2,5,6]$, with different neurotransmitters. The results are shown in Figure 5. Cholinergic stimulation of the LH by local application of acetylcholine greatly increased (about 3.5 -fold) the enzyme activity over $4 \mathrm{~h}$, as compared with that in control rats similarly treated with saline. However, similar application of other neurotransmitters, such as dopamine, norepinephrine, serotonin, GABA, histamine, and glutamic acid, did not affect the enzyme activity.

The effect of cholinergic stimulation of the LH on liver tyrosine aminotransferase was blocked completely by previous intrahypothalamic injection of atropine (Fig. 6, Expt. 1), indicating that acetylcholine-sensitive neurones of the $\mathrm{LH}$ are specifically involved in regulation of this hepatic enzyme, as in the case of liver glycogen synthetase $[11,12]$. The response of tyrosine aminotransferase to cholinergic stimulation of the LH was also suppressed by previous and additional IP injections of the peripheral cholinolytic agent, N-methylatropine (Fig. 6, Expt. 2 ), or by bilateral subdiaphragmatic vagotomy (Fig. 6, Expt. 3). These results suggest that the hypothalamic cholinergic influence on liver tyrosine aminotransferase is mediated largely by the cholinergic system in the LH-vagal pathway. Our results are consistent with the view of Black and Reis [62] that the vagal-cholinergic nerves are concerned in neural regulation of liver tyrosine aminotransferase.

\section{Hypothalamic Regulation of Lipid Metabolism in Adipose Tissue}

It has been well established that the hypothalamus is implicated in the development of obesity in experimental animals. The syndrome of hypothalamic obesity results from destruction of the ventromedial region of the hypothalamus, and accordingly, hypothalamic influences upon lipid metabolism have been directed chiefly at understanding the mechanisms underlying development of obesity after injuring the VMH. Recent advances in this field have been reviewed $[63,64]$.

At least 3 main factors contribute to genesis of this syndrome: a) Hyperphagia due to damage to the ventromedial hypothalamic "satiety centre". Ablation of this satiety centre is believed to remove the inhibitory influences of a primary feeding centre in the lateral hypothalamus and allow excess feeding [3]. The resulting excess nutrients are deposited as body fat. b) Hyperinsulinaemia chronically induced by $\mathrm{VMH}$ lesions. Increased secretion of insulin can stimulate lipogenesis in adipose tissue, resulting in

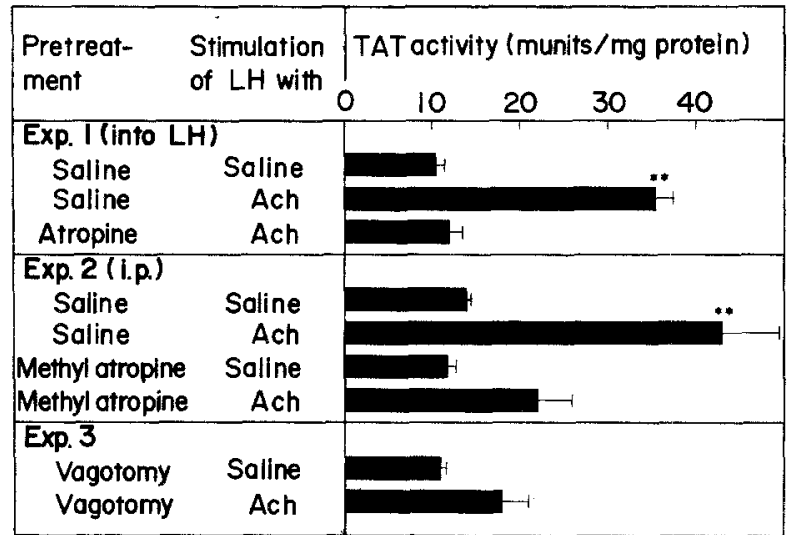

Fig. 6. Effects of central and peripheral cholinergic blockade and vagotomy on the response of liver tyrosine aminotransferase (TAT) to cholinergic stimulation of the $\mathrm{LH}$. In the first series of experiments (Exp. 1), atropine sulphate $\left(1 \times 10^{-7} \mathrm{~mol}\right.$ in $1 \mu \mathrm{l}$ of $0.154 \mathrm{~mol} / \mathrm{l}$ saline) or saline was applied to the LH, $10 \mathrm{~min}$ before intrahypothalamic injection of acetylcholine (Ach, $5 \times 10^{-8} \mathrm{~mol}$ in $1 \mu \mathrm{l}$ of $0.154 \mathrm{~mol} / 1$ saline). In the second series of experiments (Exp. 2), N-methylatropine $(10 \mathrm{mg} / \mathrm{kg}$ in $0.5 \mathrm{ml}$ of $0.154 \mathrm{~mol} / \mathrm{l}$ saline) or saline was given IP, $30 \mathrm{~min}$ before and $1 \mathrm{~h}$ after intrahypothalamic application of acetylcholine (Ach, $5 \times 10^{-8} \mathrm{~mol}$ in $1 \mu \mathrm{l}$ of $0.154 \mathrm{~mol} / \mathrm{l}$ saline). In the third series of experiments (Exp. 3), bilateral vagotomy below the diaphragm was carried out in rats 3 weeks before chemical stimulation of the $\mathrm{LH}$ with acetylcholine (Ach, $5 \times 10^{-8} \mathrm{~mol}$ in $1 \mu \mathrm{l}$ of $0.154 \mathrm{~mol} / 1 \mathrm{saline}$ ). In all series of experiments, the activity of liver tyrosine aminotransferase was measured $4 \mathrm{~h}$ after microinjection of acetylcholine. Columns and bars show means + SEM of values in 5-9 rats. ** Significantly different from the value of the control injected with saline at $P<0.01$

obesity. c) Possible derangement in the autonomic nervous system after destruction of the VMH. Since the $\mathrm{VMH}$ is part of the hypothalamic component of the sympathetic nervous system, its destruction may lead to decrease in sympathetic activity or, alternatively, increase in parasympathetic tone, which would favor reduced lipolysis and enhanced lipogenesis.

Early studies on the mechanism of the syndrome of hypothalamic obesity stressed hyperphagia as a primary factor, while hyperinsulinaemia was regarded as a secondary factor resulting from overeating [54]. Subsequent studies in weanling rats [55] and adult rats that were pair fed to prevent hyperphagia $[56,57]$, however, showed that hyperinsulinaemia due to VMH lesions was not a consequence of hyperphagia, but a primary effect, and that obesity developed even in the absence of hyperphagia.

Recently, emphasis has been put on the possible link between hyperinsulinaemia and disturbances in the hypothalamo-autonomic nervous system as an explanation of the etiology of hypothalamic obesity. Inoue et al. [65] have shown that the hyperinsulinaemia following $\mathrm{VMH}$ lesions is dependent upon intact neural innervation to the pancreatic islets and have suggested the prime importance of neural con- 


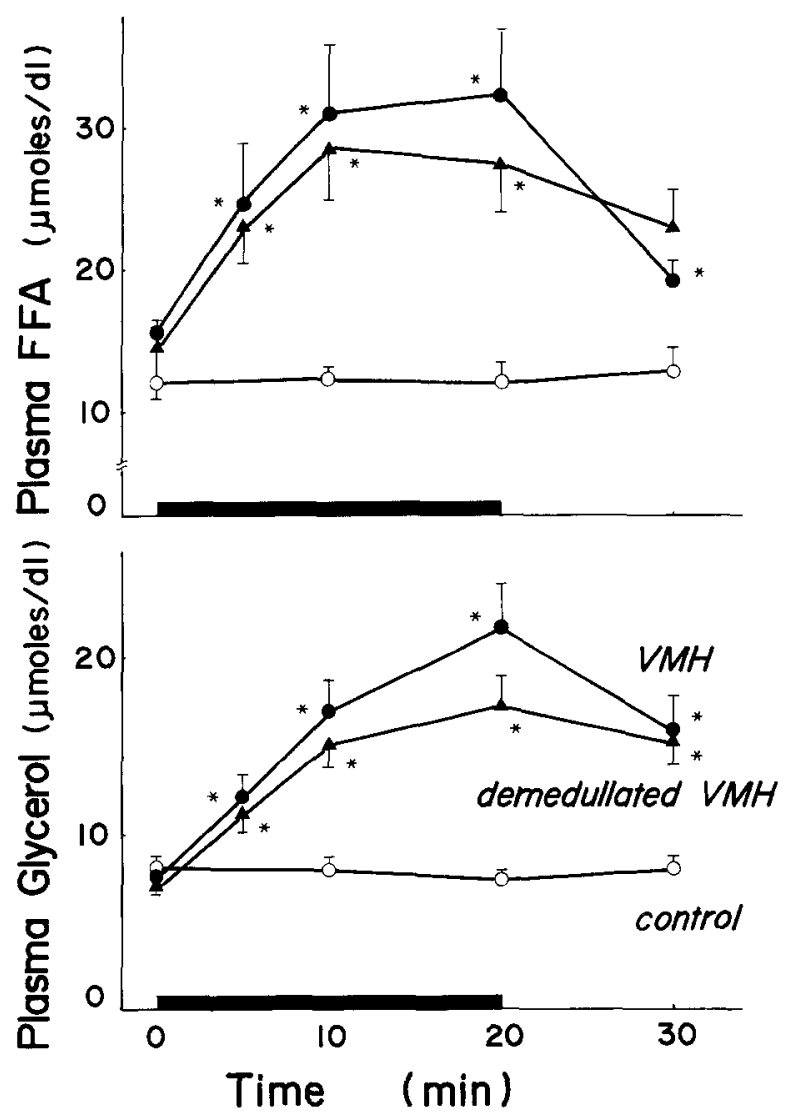

Fig. 7. Effect of electrical stimulation of the VMH on the levels of plasma glycerol and FFA in intact, and adrenal-demedullated rats under anaesthesia. The VMH of intact rats (-) and adrenaldemedullated rats $(\boldsymbol{A})$ was stimulated electrically for $30-\mathrm{s}$ periods once every minute for $20 \mathrm{~min}$, which is shown by the solid block on the abscissa. Control animals $(O)$ were not given electrical stimuli. Bilateral adrenodemedullation was performed 1 week before stimulation. Points are means $\pm \mathrm{SEM}$ of values in 5 animals. * Significantly different from the value before stimulation $(P<0.05)$

nections to the pancreas in the genesis of this type of obesity. They found that VMH lesions in diabetic rats that are cured by transplanting pancreatic tissue beneath the renal capsule do not produce hyperinsulinaemia, or induce hyperphagia and body weight gain. Possibly, the vagus nerves mediate the hyperinsulinaemia in the VMH syndrome, since the vagus nerves are known to stimulate insulin secretion and VMH lesions may increase vagal parasympathetic activity and suppress sympathetic activity. This notion is supported by the finding that rats with VMH lesions show increased-gastric acid secretion and that subdiaphragmatic vagotomy reverses the obesity and hyperinsulinaemia due to $\mathrm{VMH}$ lesions $[53,58,66]$. Diminished activity of the sympathetic nervous system may also account for the hyperinsulinaemia characteristic of this syndrome. In the light of these observations, it is most probable that obesity induced by VMH lesions is due to a primary alteration in autonomic nervous regulation of insulin secretion and subsequent stimulation of lipogenesis in adipose tissue.

As mentioned, most previous studies on hypothalamic influences upon lipid metabolism have been focused on the reason for obesity after injuring the VMH; there have been few studies on changes of lipolysis and lipogenesis in adipose tissue after stimulating the VMH and LH. Our previous studies [67] showed that electrical stimulation of the VMH caused lipolysis in rabbits, detected by a marked increase in plasma glycerol concentration, whereas electrical stimulation of the LH had no effect on lipolysis. In these experiments, however, electrical stimulation of the VMH in unanaesthetized rabbits was not associated with an increase in the concentration of plasma free fatty acids (FFA), another hydrolytic product of triglycerides, in spite of a marked elevation of plasma glycerol. Second, approximately $80 \%$ of the plasma glycerol elevation elicited by VMH stimulation was eliminated by bilateral adrenalectomy, suggesting that the adrenal medulla was principally involved in $\mathrm{VMH}$-induced lipolysis and that sympathetic innervation of the adipose tissue was subdominant in this species $[67,68]$.

We have reexamined hypothalamic regulation of lipolysis by using unanaesthetized and anaesthetized rats. In unanaesthetized rats, electrical stimulation of the VMH caused a marked increase in the concentration of plasma glycerol, but did not increase the plasma FFA concentration, confirming the previous observation in rabbits. The absence of an increase of plasma FFA in unanaesthetized animals can be attributed to either a large elevation of plasma lactate, which inhibits the release of FFA from adipose tissue by increasing the rate of reesterification, or to increased FFA utilization in muscle, since electrical stimulation of the VMH in unanaesthetized animals elicits excitement and muscular activity. In anaesthetized rats, stimulation of the $\mathrm{VMH}$ caused no increase in plasma lactate, and the plasma glycerol and FFA concentrations were both elevated markedly (Fig. 7). Again, electrical stimulation of the LH had no significant effect on plasma glycerol and FFA concentrations. Also, as shown in Figure 7, bilateral adrenodemedullation did not prevent the lipolytic response to $\mathrm{VMH}$ stimulation, although it reduced slightly the increment of plasma glycerol and FFA. However, the lipolytic response was completely blocked by previous treatment of the animals with hexamethonium or propranolol, but not with phentolamine. These results suggest that sympathetic innervation of the adipose tissue is the dominant factor involved in VMH-induced lipolysis, while the role of the adrenal medulla is subdominant in the rat; the 
effect of VMH stimulation is mainly transmitted through the sympathetic nerves to $\beta$-adrenergic receptor of the adipose tissue.

Our results are consistent with the concept that the ventromedial region of the hypothalamus acts as a regulatory centre for fat mobilization by modulating activation of the sympathetic nervous system. This concept was confirmed by the recent findings of Bray and Nishizawa $[69,70]$ that both VMH lesions and sympathetic denervation in rats attenuated the mobilization of FFA and glycerol from the adipose tissue caused by stimuli that involve the sympathetic nervous system (such as fasting, forced swimming, exposure to cold, or administration of 2-deoxyglucose), whereas lesions of the LH did not significantly change fat mobilization. This is taken to indicate that VMH lesions impair fat mobilization by reducing sympathetic tone of the fat depots, and that the obesity which follows bilateral VMH lesions may be in part due to this reduced sympathetic activity and the resulting reduction in lipolysis.

There is ample evidence that the sympathetic nervous system participates in the regulation of lipolysis. Adipose tissue is richly supplied by sympathetic nerve fibres, which are important in control of its metabolic activity, and the norepinephrine released from sympathetic nerve endings is of prime importance for lipolysis in situations requiring increased sympathetic activity, such as during cold exposure, forced muscular activity, or starvation [71]. Also, there is some evidence that direct stimulation of the sympathetic nerves causes fat mobilization from the adipose tissue: electrical stimulation of the sympathetic nerve supply of the epididymal fat pads incubated in vitro results in the rapid release of FFA and glycerol into the incubation medium [72, 73]. Stimulation of the sympathetic nerves to subcutaneous adipose tissue increases the outflow of glycerol and FFA from the tissue perfused in situ, and the effect of nerve stimulation is inhibited by $\beta$-adrenergic blocking agents and potentiated by $\alpha$-adrenergic blockade [74].

It is unknown whether hypothalamic stimulation of either the VMH or the $\mathrm{LH}$ affects lipogenesis in adipose tissue. We have investigated this problem by measuring the incorporation of radioactivity from ${ }^{14} \mathrm{C}$-glucose into fatty acids and glycerol moieties of triglycerides, in vivo. Surprisingly, on electrical stimulation of the VMH, the rate of triglyceride synthesis measured by this method increased markedly in the brown (interscapular) adipose tissue and decreased significantly in the liver, but did not change in the white (parametrial and retroperitoneal) adipose tissue of rats. Electrical stimulation of the $\mathrm{LH}$, however, did not discernibly alter the rate of triglyceride synthesis in any of the three tissues.

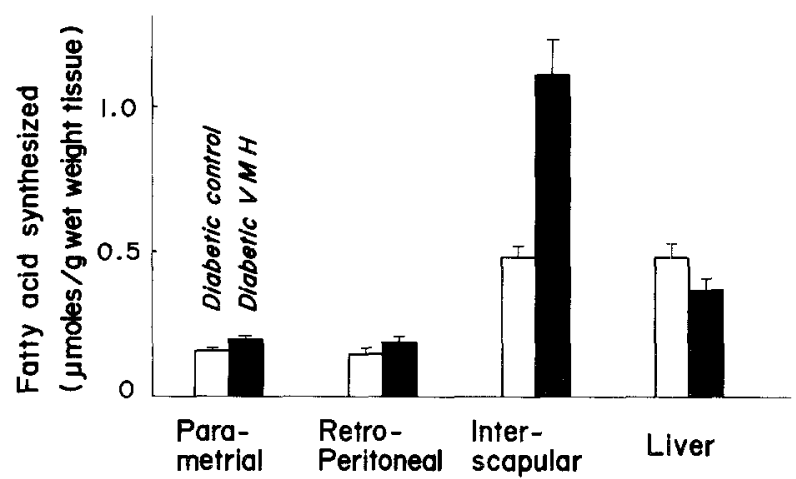

Fig. 8. Effect of electrical stimulation of the VMH on fatty acid synthesis in streptozotocin-induced diabetic rats. The VMH of rats, previously made diabetic by IV injection of streptozotocin $(65 \mathrm{mg} / \mathrm{kg})$, was stimulated electrically for 30 -s periods once every minute for $10 \mathrm{~min}$, and then the rats were injected IP with $3 \mathrm{mCi}$ of ${ }^{3} \mathrm{H}_{2} \mathrm{O}$ in $0.3 \mathrm{ml}$ of $0.154 \mathrm{~mol} / \mathrm{l}$ saline. After another 30 -min period of intermittent stimulation, they were killed and the interscapular, retroperitoneal and parametrial adipose tissues and the liver were removed and frozen rapidly. Total lipids from each tissue were hydrolyzed, and after extraction of the fatty acids, the radioactivity was measured. The rate of fatty acid synthesis was calculated from the radioactivity in fatty acids and in the plasma obtained at the time of death. Columns and bars are means and SEM of values in 8 animals

For confirmation of these findings we repeated the experiments using ${ }^{3} \mathrm{H}_{2} \mathrm{O}$ as a radioactive precursor and measured the incorporation of tritium into fatty acids of triglycerides [75]. This latter technique is the most reliable method for measuring the rate of fatty acid biosynthesis because it is independent of the carbon precursor. The rate of fatty acid synthesis in control rats was about 4 times greater in brown adipose tissue than in white adipose tissue. With electrical stimulation of the $\mathrm{VMH}$, the rate increased more (about 2.3 times that of unstimulated controls) in the interscapular adipose tissue, but not in the parametrial and retroperitoneal adipose tissues. Again, electrical stimulation of the LH did not appreciably affect lipid synthesis in either type of adipose tissue.

Enhanced lipid synthesis in brown adipose tissue upon VMH stimulation was also observed in rats previously made diabetic by streptozotocin-treatment (Fig. 8): the rate of fatty acid synthesis in the two types of adipose tissue and in the liver of diabetic control rats was reduced to below half the values in healthy control rats, possibly owing to lack of the lipogenic action of insulin. Nonetheless, electrical stimulation of the VMH of the diabetic rats markedly increased the rate in interscapular brown adipose tissue. There was no significant increase in the lipogenic response in either retroperitoneal or parametrial white adipose tissue, and conversely fatty acid synthesis in the liver decreased slightly, though not significantly, with stimulation of the VMH. 
These results indicate that stimulation of the VMH enhances lipogenesis in brown adipose tissue preferentially, through a mechanism not involving insulin. This effect is probably mediated by sympathetic innervation of brown adipose tissue, because the VMH is presumed to be part of the sympathetic neural output from the hypothalamus. Brown adipose tissue, which is found in specific anatomical locations such as the interscapular area, the mediastinum, and along the aorta and vertebral column, has abundant sympathetic innervation with adrenergic fibres which form nest-like networks around every fat cell. On the other hand, white adipose tissue contains no adrenergic fibres except those related to the blood vessels, and consequently its norepinephrine content is much lower than that of brown adipose tissue [76]. Therefore, norepinephrine may be a mediator of the effect of VMH stimulation on lipogenesis in brown adipose tissue. However, it is also possible that some lipogenic factor(s) released from the hypothalamus acts on brown fat cells; such a factor has recently been suggested to be present in an extract of bovine hypothalamus [77].

Our results, together with the observation of increased lipolysis in adipose tissue after VMH stimulation, suggest that both the breakdown and resynthesis, i. e., the turnover, of triglycerides in brown adipose tissue, but not in white adipose tissue, are accelerated by stimulation of the VMH. Since brown adipose tissue is an important fat depot for physiological lipolysis mediated by the sympathetic nerves, especially during cold acclimatization, this could also explain the increased lipid turnover in the brown adipose tissue of cold-acclimatized animals [78]. Although electrical stimulation of the LH fails to alter lipid synthesis in white adipose tissue, it cannot exclude a possible implication of the LH in control of lipogenesis; for neuronal organization of the LH is complex, its electrical stimulation may mask the actual effect. Further investigations are needed to explore this possibility by selective stimulation of neurones in the $\mathrm{LH}$.

Acknowledgements. Much of the original work reported here was done at the Division of Neurochemistry, Psychiatric Research Institute of Tokyo. I am grateful to my collaborators, Drs. A. Kumon, H. Matsushita, S. Tokutake, K. Ishikawa, A. Takahashi, M. Usami and M. Ozawa for their contributions to these studies.

\section{References}

1. Shimazu T, Amakawa A (1968) Regulation of glycogen metabolism in liver by the autonomic nervous system. II. Neural control of glycogenolytic enzymes. Biochim Biophys Acta 165: 335-348

2. Shimazu T (1979) Nervous control of peripheral metabolism. Acta Physiol Pol 30 [Suppl 18]: 1-18
3. Anand BK (1961) Nervous regulation of food intake. Physiol Rev 41: 677-708

4. Oomura Y (1973) Central mechanism of feeding. In: Kotani $M$ (ed) Advances in biophysics, vol 5. University of Tokyo Press, Tokyo, p 65-142

5. Ban T (1966) The septo-preoptico-hypothalamic system and its autonomic function. Prog Brain Res 21 A: 1-43

6. Ban T (1975) Fiber connections in the hypothalamus and some autonomic functions. Pharmacol Biochem Behav 3 [Suppl 1]: $3-13$

7. Shimazu $T$ (1977) Reciprocal functions of the ventromedial and lateral hypothalamic nuclei in regulating carbohydrate metabolism in liver, and their relevance to food intake control. In: Katsuki Y, Sato M, Takagi SF, Oomura Y (eds) Food intake and chemical senses. University of Tokyo Press, Tokyo, p 575-585

8. Shimazu T, Matsushita H, Ishikawa K, Takahashi A (1977) Role of the hypothalamico-autonomic nervous system in homeostatic regulation of body metabolism. In: Proc. XVIII Int Congr Neurovegetative Res, Tokyo, p 76-78

9. Shimazu T, Fukuda A, Ban T (1966) Reciprocal influences of the ventromedial and lateral hypothalamic nuclei on blood glucose level and liver glycogen content. Nature 210: $1178-1179$

10. Shimazu T, Matsushita H, Ishikawa K (1978) Hypothalamic control of liver glycogen metabolism in adult and aged rats. Brain Res 144: 343-352

11. Shimazu T, Matsushita H, Ishikawa K (1976) Cholinergic stimulation of the rat hypothalamus: effects on liver glycogen synthesis. Science 194: 535-536

12. Matsushita $H$, Ishikawa K, Shimazu T (1979) Chemical coding of the hypothalamic neurones in metabolic control. I. Acetylcholine-sensitive neurones and glycogen synthesis in liver. Brain Res 163: 253-261

13. Shimazu T, atsushita $H$ (1979) Role of the norepinephrineand acetylcholine-sensitive neurons of the hypothalamus in the regulation of hepatic metabolism. In: Usdin E, Kopin IJ, Barchas J (eds) Catecholamines: Basic and clinical frontiers, vol I. Pergamon Press, New York, p 980-982

14. Matsushita H, Shimazu T (1980) Chemical coding of the hypothalamic neurones in metabolic control. II. Norepinephrine-sensitive neurones and glycogen breakdown in liver. Brain Res 183: 79-87

15. Shimazu T, Amakawa A (1968) Regulation of glycogen metabolism in liver by the autonomic nervous system. III. Differential effects of sympathetic-nerve stimulation and of catecholamines on liver phosphorylase. Biochim Biophys Acta 165: 349-356

16. Shimazu T, Amakawa A (1975) Regulation of glycogen metabolism in liver by the autonomic nervous system. VI. Possible mechanism of phosphorylase activation by the splanchnic nerve. Biochim Biophys Acta $385: 242-$ 256

17. Rosenberg FJ, DiStefano V (1962) A central nervous system component of epinephrine hyperglycemia. Am J Physiol 203: $782-788$

18. Ezdinli EZ, Javid R, Owens G, Sokal JE (1968) Effect of high spinal cord section on epinephrine hyperglycemia. Am J Physiol 214: 1019-1024

19. Shimazu T, Fujimoto $T$ (1971) Regulation of glycogen metabolism in liver by the autonomic nervous system. IV. Neural control of glycogen biosynthesis. Biochim Biophys Acta 252: 18-27

20. Shimazu T (1971) Regulation of glycogen metabolism in liver by the autonomic nervous system. $V$. Activation of glycogen synthetase by vagal stimulation. Biochim Biophys Acta 252: $28-38$

21. Shimazu T, Ogasawara S (1975) Effects of hypothalamic 
stimulation on gluconeogenesis and glycolysis in rat liver. Am J Physiol 228: 1787-1793

22. Frohman LA, Bernardis LL (1971) Effect of hypothalamic stimulation on plasma glucose, insulin, and glucagon levels. Am J Physiol 221: 1596-1603

23. Yamada E (1965) Some observations on the nerve terminal on the liver parenchymal cell of the mouse as revealed by electron microscopy. Okajimas Folia Anat Jpn 40: 663-677

24. Forssmann WG, Ito S (1977) Hepatocyte innervation in primates. J Cell Biol 74: 299-313

25. Sawchenko PE, Friedman MI (1979) Sensory functions of the liver: a review. Am J Physiol 236: R5-R20

26. Niijima A (1969) Afferent impulse discharges from glucoreceptors in the liver of the guinea pig. Ann N Y Acad Sci 157: $690-700$

27. Peñaloza-Rojas JH, Russek M (1963) Anorexia produced by direct-current blockade of the vagus nerve. Nature 200: 176

28. Novin D, Sanderson JD, VanderWeele DA (1974) The effect of isotonic glucose on eating as a function of feeding condition and infusion site. Physiol Behav 13: 3-7

29. Schmitt M (1973) Influences of hepatic portal receptors on hypothalamic feeding and satiety centers. Am J Physiol 225: 1089-1095

30. Novin D, Gonzalez MF, Sanderson JD (1976) Paradoxical increased feeding following glucose infusions in recovered lateral rats. Am J Physiol 230: 1084-1089

31. Jeanningros R, Mei N (1980) Vagal and splanchnic effects at the level of the ventromedian nucleus of the hypothalamus (VMH) in the cat. Brain Res 185: 239-251

32. Shimazu T, Fukuda A (1965) Increased activities of glycogenolytic enzymes in liver after splanchnic-nerve stimulation. Science 150: 1607-1608

33. Edwards AV, Silver M (1970) The glycogenolytic response to stimulation of the splanchnic nerves in adrenalectomized calves. J Physiol (Lond) 211: 109-124

34. Edwards AV (1972) The sensitivity of the hepatic glycogenolytic mechanism to stimulation of the splanchnic nerves. J Physiol (Lond) 220: 315-334

35. Edwards AV (1972) The hyperglycaemic response to stimulation of the hepatic sympathetic innervation in adrenalectomized cats and dogs. J Physiol (Lond) 220: 697-710

36. Niijima A, Fukuda A (1973) Release of glucose from perfused liver preparation in response to stimulation of the splanchnic nerves in the toad. Jpn J Physiol 23: 497-508

37. Seydoux J, Brunsmann MJA, Jeanrenaud B, Girardier L (1979) $\alpha$-Sympathetic control of glucose output of mouse liver perfused in situ. Am J Physiol 236: E323-E327

38. Proost C, Carton H, De Wulf $H$ (1979) The $\alpha$-adrenergic control of rabbit liver glycogenolysis. Biochem Pharmacol 28: 2187-2191

39. Exton JH (1980) Mechanisms involved in $\alpha$-adrenergic phenomena: role of calcium ions in actions of catecholamines in liver and other tissues. Am J Physiol 238: E3--E12

40. Jones LM, Michell RH (1978) Stimulus-response coupling at $\alpha$-adrenergic receptors. Biochem Soc Trans 6: 673-688

41. Morita S, Irie Y, Saitoh Y, Kohri H (1976) Evaluation of a new beta-adrenergic blocking agent, carteolol, based on metabolic responses in rats. I. Blockade in vivo of epinephrine- and isoproterenol-induced alterations of blood concentrations of carbohydrate and lipid intermediary metabolites. Biochem Pharmacol 25: 1837-1842

42. Van de Werve G, Hue L, Hers HG (1977) Hormonal and ionic control of the glycogenolytic cascade in rat liver. Biochem $\mathrm{J}$ 162: 135-142

43. Cohen P, Burchell A, Foulkes JG, Cohen PTW, Vanaman TC, Nairn AC (1978) Identification of the $\mathrm{Ca}^{2+}$-dependent modulator protein as the fourth subunit of rabbit skeletal muscle phosphorylase kinase. FEBS Lett 92: 287-293
44. Shimazu T, Tokutake S, Usami M (1978) Inactivation of phosphorylase phosphatase by a factor from rabbit liver and its chemical characterization as glutathione disulfide. J Biol Chem 253: 7376-7382

45. Usami M, Matsushita H, Shimazu T (1980) Regulation of liver phosphorylase phosphatase by glutathione disulfide. J Biol Chem 255: 1928-1931

46. Shimazu T (1967) Glycogen synthetase activity in liver: regulation by the autonomic nerves. Science 156: 1256-1257

47. Ottolenghi C, Caniato A, Barnabei O (1971) Effect of acetylcholine on glycogen formation and the activity of glycogen synthetase in isolated perfused rat liver. Nature 229: 420-422

48. Akpan JO, Gardner R, Wagle SR (1974) Studies on the effects of insulin and acetylcholine on activation of glycogen synthase and glycogenesis in hepatocytes isolated from normal fed rats. Biochem Biophys Res Commun 61: 222-229

49. Mondon CE, Burton SD (1971) Factors modifying carbohydrate metabolism and effect of insulin in perfused rat liver. Am J Physiol 220: 724-734

50. Woods SC, Porte D Jr (1974) Neural control of the endocrine pancreas. Physiol Rev 54: 596-619

51. Gerich JE, Charles MA, Grodsky GM (1976) Regulation of pancreatic insulin and glucagon secretion. Annu Rev Physiol 38: $353-388$

52. Shimazu T, Ishikawa K (1979) Hypothalamic control of endocrine pancreas. Neurosci Lett [Suppl] 2: S50

53. Berthoud HR, Jeanrenaud B (1979) Acute hyperinsulinemia and its reversal by vagotomy after lesions of the ventromedial hypothalamus in anesthetized rats. Endocrinology 105: 146-151

54. Hales CN, Kennedy GC (1964) Plasma glucose, non-esterified fatty acid and insulin concentrations in hypothalamic-hyperphagic rats. Biochem J 90: 620-624

55. Frohman LA, Bernardis LL, Schnatz JD, Burek L (1969) Plasma insulin and triglyceride levels after hypothalamic lesions in weanling rats. Am J Physiol 216: 1496-1501

56. Han PW, Frohman LA (1970) Hyperinsulinemia in tube-fed hypophysectomized rats bearing hypothalamic lesions. Am $\mathbf{J}$ Physiol 219: 1632-1636

57. Hustvedt BE, Løvø A (1972) Correlation between hyperinsulinemia and hyperphagia in rats with ventromedial hypothalamic lesions. Acta Physiol Scand 84: 29-33

58. Inoue S, Bray GA (1977) The effects of subdiaphragmatic vagotomy in rats with ventromedial hypothalamic obesity. Endocrinology 100: 108-114

59. De Jong A, Strubbe JH, Steffens AB (1977) Hypothalamic influence on insulin and glucagon release in the rat. Am J Physiol 233: E380-E388

60. Shimazu $T$ (1962) The effect of electric stimulation of hypothalamus on rabbit liver tryptophan pyrrolase. Biochim Biophys Acta 65: 373-375

61. Shimazu T (1964) Role of the hypothalamus in the induction of tryptophan pyrrolase activity in rabbit liver. $\mathbf{J}$ Biochem (Tokyo) 55: 163-171

62. Black IB, Reis DJ (1971) Cholinergic regulation of hepatic tyrosine transaminase activity. J Physiol (Lond) 213: 421-433

63. Bernardis LL Goldman JK (1976) Origin of endocrinemetabolic changes in the weanling rat ventromedial syndrome. J Neurosci Res 2: 91-116

64. Bray GA, York DA (1979) Hypothalamic and genetic obesity in experimental animals: an autonomic and endocrine hypothesis. Physiol Rev 59: 719-809

65. Inoue S, Bray GA, Mullen YS (1978) Transplantation of pancreatic $\beta$-cells prevents development of hypothalamic obesity in rats. Am J Physiol 235: E266-E271

66. Powley TL, Opsahl CA (1974) Ventromedial hypothalamic obesity abolished by subdiaphragmatic vagotomy. Am J Physiol 226: 25-33 
67. Kumon A, Takahashi A, Hara T, Shimazu T (1976) Mechanism of lipolysis induced by electrical stimulation of the hypothalamus in the rabbit. J Lipid Res 17: 551-558

68. Kumon A, Takahashi A, Köri-Hara T (1977) Epinephrine: a mediator of plasma glycerol elevation by hypothalamic stimulation. Am J Physiol 233: E369-E373

69. Nishizawa Y, Bray GA (1978) Ventromedial hypothalamic lesions and the mobilization of fatty acids. J Clin Invest 61 : 714-721

70. Bray GA, Nishizawa Y (1978) Ventromedial hypothalamus modulates fat mobilization during fasting. Nature 274: 900-902

71. Havel RJ (1965) Autonomic nervous system and adipose tissue. In: Renold AE, Cahill Jr GF (eds) Handboock of physiology, section 5: Adipose tissue. American Physiological Society, Washington DC, p 575-582

72. Correll JW (1963) Adipose tissue: ability to respond to nerve stimulation in vitro. Science 140: $387-388$

73. Weiss B, Maickel RP (1968) Sympathetic nervous control of adipose tissue lipolysis. Int $J$ Neuropharmacol 7: 395-403

74. Fredholm B, Rosell S (1968) Effects of adrenergic blocking agents on lipid mobilization from canine subcutaneous adipose tissue after sympathetic nerve stimulation. J Pharmacol Exp Ther 159: 1-7

75. Shimazu T, Takahashi A (1980) Stimulation of hypothalamic nuclei has differential effects on lipid synthesis in brown and white adipose tissue. Nature 284: 62-63

76. Daniel H, Derry DM (1969) Criteria for differentiation of brown and white fat in the rat. Can J Physiol Pharmacol 47: 941-945

77. Grimes LJ, Mok C, Martin IM (1978) Effect of a bovine hypothalamic extract on glucose utilization by rat adipocytes. Am J Physiol 234: E554-E559

78. Himms-Hagen J (1965) Lipid metabolism in warm-acclimated and cold-acclimated rats exposed to cold. Can J Physiol Pharmacol 43: 379-403

Takashi Shimazu, M. D.

Department of Medical Biochemistry

School of Medicine, Ehime University

Shigenobu, Ehime 791-02

Japan

\section{Discussion after Shimazu's Presentation}

Porte: You mentioned one observation very rapidly, but it is very interesting. Did you indeed find that the neural stimulation to the liver is blocked with indomethacin but is not blocked by alpha- or beta-adrenergic blockers?

Shimazu: That is true.

Porte: Then can you produce your effect with infused catecholamines; and if so, are blockers effective; and does this imply that there is something special about the NE released from nerve terminals?

Shimazu: When we administered NE into the portal vein, there was a rapid increase of phosphorylase activity, and this could be blocked with beta-blockers.

Porte: Have you measured prostaglandin release when you have stimulated the nerves to the liver? And have you tried any other prostaglandin synthesis inhibitors?

Shimazu: Not yet.

Van Houten: Several years ago, it was reported that when small amounts of insulin are administered into the basal hypothalamus, there is a rapid systemic hypoglycemia (Brain Res (1975) 96: 156). Have you put insulin into the VMH and measured hepatic enzymes? One might expect insulin to interact with the effects of NE in the hypothalamus (Am J Physiol (1979) 236: R312).

Shimazu: We would predict that the local administration of insulin into the VMH would decrease phosphorylase activity in the liver, but we haven't done the experiment.

B. Jeanrenaud: When you stimulated the $\mathrm{LH}$ and the VMH electrically, what happened to insulin levels?
Shimazu: When we stimulated the VMH electrically, both insulin and glucagon went up. Glucagon went up very soon after we began the stimulation; insulin remained at basal levels until the stimulation was over and then increased. When we stimulated the LH electrically, neither insulin nor glucagon changed.

B. Jeanrenaud: What does chemical stimulation of the hypothalamus do to glucagon levels?

Shimazu: When acetylcholine was put into the VMH, insulin didn't change but there was an increase of glucagon which was blocked with hexamethonium, so I think the response is nicotinic in nature. Administration of epinephrine caused an increase of both insulin and glucagon, as did the administration of norepinephrine. The effect after nor-epinephrine was very small. Other transmitters had no effect on either hormone.

At the LH, only epinephrine caused an increase of insulin. Nothing else had any effect.

Steffens: As will be shown later, when we stimulated the LH with acetylcholine, insulin levels increased; and when we put in norepinephrine, there was also an increase of insulin. Since insulin itself is such a potent stimulator of liver glycogen synthetase activity, one would expect a large increase of that enzyme after NE was put into the LH, but you evidently observed only a small increase. How do you account for this?

Shimazu: You are correct, the response was very small. I think that with our preparation, we see mainly the direct neural effects at the liver. 